\title{
Improved survival in heart transplant patients living at high altitude
}

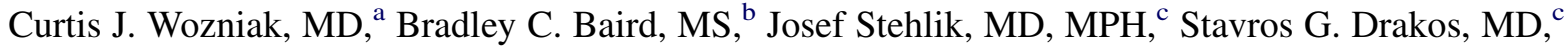 \\ David A. Bull, MD, ${ }^{\mathrm{a}}$ Amit N. Patel, MD, MS, ${ }^{\mathrm{a}}$ and Craig H. Selzman, MD ${ }^{\mathrm{a}}$
}

Objective: Higher altitudes are associated with chronic hypoxia and elevated pulmonary vascular resistance, both potentially detrimental to patients requiring heart transplantation. The purpose of the present study was to determine whether altitude negatively affects survival among patients undergoing heart transplantation.

\begin{abstract}
Methods: The United Network of Organ Sharing database for adult patients undergoing heart transplantation from 1990 to 2008 ( $n=36,529)$ was analyzed, and each patient was assigned an altitude according to their home ZIP code. Survival was compared between patients at less than $2000 \mathrm{ft}, 2000$ or more to less than $4000 \mathrm{ft}$, and $4000 \mathrm{ft}$ or more. Adjusted survival was calculated using Cox proportional hazards analysis with propensity-matched stratification.

Results: Patients living at above $2000 \mathrm{ft}$ had a $16 \%$ reduction in the risk of death at 1 year after transplant $(P=.006)$ compared with those at lower altitudes. At 5 and 10 years, the risk reduction was $6 \%(P=.21)$ and $6 \%(P=.114)$, respectively. Among patients living above $4000 \mathrm{ft}$, the $1-, 5-$, and 10 -year reduction in the risk of death was $20 \%(P=.022), 12 \%(P=.057)$, and $15 \%(P=.0052)$ compared with those living below $2000 \mathrm{ft}$, respectively. Patients at high altitude had a lower incidence of diabetes, used tobacco less often, and accounted for the greatest proportion of status 2 heart transplants. Comparing the factors predicting survival at high and low altitudes, patients with a status $1 \mathrm{~A}$ listing had improved outcomes at higher altitudes.
\end{abstract}

Conclusions: Patients living above $2000 \mathrm{ft}$ have improved survival after heart transplantation, an advantage even more pronounced at $4000 \mathrm{ft}$. Although the mechanism of protection remains unclear, the findings might reflect differences in pre-2006 organ allocation. (J Thorac Cardiovasc Surg 2012;143:735-41)

Supplemental material is available online.

A number of epidemiologic studies have suggested that patients with cardiovascular disease who live at higher altitudes have improved survival compared with patients living at lower elevations. ${ }^{1-4}$ Multiple factors determine whether a high altitude exerts harm or benefit to cardiovascular health. Environmental factors such as duration (acute, chronic, or intermittent exposure), perinatal exposure, and the absolute level of altitude each play a role. ${ }^{5}$ Individual comorbidities and habits, such as tobacco abuse and exercise, interact with the environmental factors to determine the host response to altitude.

Physiologically, altitude is associated with an increased cardiac output, ejection fraction, and coronary blood

\footnotetext{
From the Division of Cardiothoracic Surgery, ${ }^{a}$ Department of Pediatrics, ${ }^{\mathrm{b}}$ and Division of Cardiology, ${ }^{\mathrm{c}}$ University of Utah, Salt Lake City, Utah.

Disclosures: Authors have nothing to disclose with regard to commercial support.

Read at the 37th Annual Meeting of The Western Thoracic Surgical Association, Colorado Springs, Colorado, June 22-25, 2011.

Received for publication June 22, 2011; revisions received Oct 3, 2011; accepted for publication Nov 8, 2011; available ahead of print Dec 12, 2011.

Address for reprints: Craig H. Selzman, MD, Division of Cardiothoracic Surgery,

University of Utah, 30 North 1900 East, SOM 3C 127, Salt Lake City, UT

84132-2101 (E-mail: craig.selzman@hsc.utah.edu).

$0022-5223 / \$ 36.00$

Copyright (c) 2012 by The American Association for Thoracic Surgery

doi:10.1016/j.jtcvs.2011.11.012
}

flow, ${ }^{6-8}$ which might provide a beneficial cardioadaptive effect. In contrast, a high altitude is also associated with increased sympathetic activity, hypocarbia, chronic hypoxic pulmonary vasoconstriction, right ventricular hypertrophy, and both systemic and pulmonary hypertension. ${ }^{9-11}$ These latter attributes intuitively seem harmful to patients with advanced heart failure and, in particular, patients requiring heart transplantation.

Although several case reports have reported heart transplant patients traveling to high altitudes and successfully exercising, ${ }^{12-14}$ these anecdotes do not address the issue related to heart transplantation in patients living at elevation. Pulmonary artery hypertension is a well-documented contraindication to heart transplantation because the donor right ventricle that is acutely asked to pump against a highresistance vascular bed will fail. The outcomes in patients with right ventricular failure after heart transplantation are dismal. ${ }^{15-17}$ Thus, the purpose of the present study was to determine the influence of altitude on survival after heart transplantation. Although patients with coronary artery disease might fare well living at higher elevations, we hypothesized that the detrimental effects of altitude on the pulmonary vasculature would negatively affect patients undergoing heart transplantation and result in reduced short- and long-term survival.

\section{METHODS}

The United Network of Organ Sharing (UNOS) patient database (Standard Transplant Analysis and Research) was analyzed. The data file 


\section{Abbreviations and Acronyms \\ LVAD $=$ left ventricular assist device \\ UNOS $=$ United Network of Organ Sharing}

contained no identifying patient data nor transplant center identifiers. Adult patients ( $\geq 18$ years old) undergoing orthotopic heart transplantation in the United States from 1990 to 2008 were included. Pre-1990 patient data were not used, given the modern advances in immunosuppressive and prophylactic regimens. Patients undergoing combined or redo transplantation were excluded. Using a commercially available ZIP code database (www. zipcodeworld.com), each patient in the UNOS database was assigned an altitude according to their home ZIP code.

The patients were stratified into 3 groups according to their home altitude: less than $2000 \mathrm{ft}, 2000 \mathrm{ft}$ or more to less than $4000 \mathrm{ft}$, and $4000 \mathrm{ft}$ or higher. The strata were selected to assess the effect of "moderate" and "extreme" altitude in the context of the U.S. geography. Relative to worldwide elevations, all our patients would be considered to live at a "moderate" altitude.

The baseline demographic and clinical data were recorded. A comparison of the baseline patient characteristics was performed using analysis of variance for continuous variables and chi-square contingency table analysis for dichotomous variables. The primary end point was all-cause mortality. Post-transplant survival was compared between those living above and below $2000 \mathrm{ft}$. To assess the effect of "extreme" altitude, additional comparison was made between the patients living below $2000 \mathrm{ft}$ and those living above $4000 \mathrm{ft}$. Although we described the patient cohort in the intermediate group (2000-4000 ft), we focused our analysis on the 4000-ft or higher group to compare 2 highly contrasting populations. Cox proportional hazards analysis with propensity-matched stratification was used to construct survival models to determine whether altitude was an independent predictor of survival. Survival models were adjusted for age, gender, body mass index, listing status (status 1A/B vs status 2), wait list time, the presence of a left ventricular assist device (LVAD), mean pulmonary artery pressures, ischemic time, antigen matching, panel reactive antibody, diabetes, and oxygen consumption. The incidence of acute rejection was unable to be reliably determined owing to the marked variations in reporting and the numerous missing values in the database.

Hazard ratios from the Cox proportional hazards models identified the factors predicting survival. These factors were compared between the high and low altitude strata using an independent samples $t$ test. In that analysis, a survival factor (eg, age) that explained death could potentially have been significant within each group but was only considered significant if the magnitude of the effect between groups differed significantly. A second Cox proportional hazards model without propensity-matched stratification was also constructed, and the survival factors from that analysis are included online (Tables E1 and E2). The proportional hazards assumption was tested using time interaction covariates. No significant deviation from proportional hazards was observed for either altitude comparison.

Significance was set to reflect a $95 \%$ confidence interval for all analyses. Statistical analysis was performed using SAS, version 9.2 (SAS Institute, Chicago, Ill).

\section{RESULTS}

A total of 36,259 patients were included in the present study. The preoperative patient characteristics among the 3 altitude strata are listed in Table 1. As expected, the vast majority of patients lived below $2000 \mathrm{ft}$. No differences were found with respect to gender or the proportion of patients receiving mechanical support with a left ventricular assist device. More patients at lower altitudes had diabetes, used tobacco, and were listed and waited with greater urgency status. In contrast, the patients at altitude and, in particular, those living at about $4000 \mathrm{ft}$, more often had 2, had greater oxygen consumption, and had fewer comorbidities. Compared with the lower elevation groups, the higher elevation group appeared to be more sensitized. Perhaps, unexpectedly, the mean pulmonary artery pressures in those at altitude were actually lower than in those at a lower elevation.

Figure 1 depicts the survival curves for patients living above and below $2000 \mathrm{ft}$ at 1,5 , and 10 years after transplantation. Both groups shared the initial perioperative decrease in survival. However, the curves began to diverge within 30 days of transplant. Because $2000 \mathrm{ft}$ is a relatively low bar for altitude, we also studied patients who were at even higher elevations. Figure 2 depicts survival curves for patients living below $2000 \mathrm{ft}$ and those living above $4000 \mathrm{ft}$ at 1,5 , and 10 years after transplantation. The survival benefit of altitude was similarly observed in this extreme group, both early after surgery and sustained long term.

To quantify the observed benefit of the higher elevations, propensity-matched survival models were used to test whether altitude was an independent predictor of survival, and adjusted hazard ratios were calculated for each group (Figure 3). Patients living above $2000 \mathrm{ft}$ had a $16 \%$ reduction in the risk of death at 1 year after transplant $(P=.006)$. A trend, albeit not significant, was seen for a sustained benefit at $5(6 \%$ reduction, $P=.21)$ and $10(6 \%$ reduction, $P=.114$ ) years after transplantation. Among patients living above $4000 \mathrm{ft}$, a significant risk reduction was observed. Compared with patients living at below $2000 \mathrm{ft}$, patients living above $4000 \mathrm{ft}$ had a $20 \%(P=.022), 12 \%(P=.057)$, and $15 \%(P=.0052)$ risk reduction achieved at 1,5 , and 10 years after transplantation.

To identify the factors that contributed to the increased survival in the high elevation group, the hazard ratios obtained from the Cox proportional hazards models with propensity-matched stratification were compared between the high and low groups. Multiple factors were identified that predicted death within either the high or low altitude group at nearly every point. For example, elevated pulmonary artery pressures, ischemic time, and HLA mismatch all predictably contributed to mortality within each stratum. However, when comparing these factors between strata, few factors were significantly different (Tables 2 and 3). Comparing patients living above and below $2000 \mathrm{ft}$, diabetes was associated with improved survival among patients living at a higher elevation at 5 and 10 years (Table 2). This effect did not persist when comparing patients above $4000 \mathrm{ft}$. Longer wait times, male gender, and lower maximal exercise oxygen consumption were 
TABLE 1. Baseline characteristics of patients undergoing heart transplantation

\begin{tabular}{|c|c|c|c|c|}
\hline Characteristic & $<2000 \mathrm{ft}$ & $2000-4000 \mathrm{ft}$ & $>4000 \mathrm{ft}$ & $P$ value \\
\hline Patients (n) & $34,236(94)$ & $1229(3)$ & $1079(3)$ & \\
\hline Age (y) & $51 \pm 12$ & $52 \pm 11$ & $50 \pm 13$ & $<.001$ \\
\hline Male $(\%)$ & 76.4 & 76.9 & 78.9 & .18 \\
\hline Body mass index $\left(\mathrm{kg} / \mathrm{m}^{2}\right)$ & $24.5 \pm 7.7$ & $25 \pm 7$ & $23.9 \pm 7.4$ & .0017 \\
\hline Diabetes $(\%)$ & 16.2 & 15.3 & 10.9 & $<.001$ \\
\hline Cigarette use $(\%)$ & 13.3 & 11.9 & 8.9 & $<.0001$ \\
\hline $\mathrm{VO}_{2} \mathrm{Max}(\mathrm{mL} / \mathrm{min} / \mathrm{kg})$ & $1.9 \pm 4.5$ & $2.1 \pm 4.8$ & $2.6 \pm 5.2$ & $<.0001$ \\
\hline LVAD at listing (\%) & 2.5 & 2 & 2.5 & .52 \\
\hline Status 1A (n) & $7578(22)$ & $207(16.8)$ & $140(13)$ & $<.0001$ \\
\hline Status 1B (n) & $7450(22)$ & $258(21)$ & $198(18.3)$ & $<.02$ \\
\hline Status $2(\mathrm{n})$ & $19,228(56)$ & $773(62.8)$ & $744(68.7)$ & $<.0001$ \\
\hline Status 1A duration (days) & $6.9 \pm 20$ & $4.1 \pm 11.7$ & $3.7 \pm 13$ & $<.0001$ \\
\hline Status 2 duration (days) & $127.8 \pm 248$ & $142 \pm 274$ & $133 \pm 227$ & .117 \\
\hline Mean PAP (mm Hg) & $22 \pm 17$ & $22 \pm 17$ & $19.9 \pm 16$ & .0002 \\
\hline HLA mismatch level & $3.8 \pm 2$ & $3.9 \pm 1.9$ & $4 \pm 1.7$ & $<.0001$ \\
\hline Most recent PRA (\%) & $2.4 \pm 10.8$ & $2.5 \pm 11.3$ & $3.18 \pm 12.9$ & .0753 \\
\hline Ischemic time (h) & $2.8 \pm 1.2$ & $3 \pm 1.3$ & $2.9 \pm 1.3$ & $<.0001$ \\
\hline
\end{tabular}

Data in parentheses are percentages. $L V A D$, Left ventricular assist device; $V O_{2}$ Max, maximal exercise oxygen consumption; $P A P$, pulmonary artery pressure; $H L A$, human leukocyte antigen; $P R A$, panel of reactive antibodies.

associated with worse survival for patients above $2000 \mathrm{ft}$, with an inconsistent effect over time. The only 2 factors contributing to survival among patients living above 4000 $\mathrm{ft}$ were a designation of status $1 \mathrm{~A}$ and the duration of status 1A (Table 3). For these patients, a status 1A designation was associated with improved survival. Similar to the analysis of patients living above and below $2000 \mathrm{ft}$, longer 1A times were associated with worse survival, and although the effect was observed at 5 and 10 years, the effect was only a $1 \%$ difference.

\section{DISCUSSION}

The principle finding in the present study was improved survival among heart transplant patients who live at higher altitudes. The benefit appeared to begin at $2000 \mathrm{ft}$ and was even more marked in patients living above $4000 \mathrm{ft}$. These observations contradict our initial hypothesis. We postulated that heart transplant patients living at a higher altitude would be particularly susceptible to the increased cardiac workload incurred by altitude-induced hypoxia and pulmonary vasoconstriction, a sequence that would ultimately result in poorer survival. Although the presence of pulmonary hypertension negatively influenced survival within each elevation strata, the pulmonary artery pressures were actually the same or slightly lower in the higher altitude group, and pulmonary artery pressure was not a significant factor when comparing survival characteristics between the high and low elevation groups. As such, pulmonary hypertension likely does not account for all our results.

A cursory view of the descriptive characteristics between our groups would suggest that the low altitude cohort were more ill (eg, more patients with diabetes, those who smoked, and patients with status IA) and, thus, predictably did worse. Our survival models, however, were propensity matched and designed to account for differences at baseline, grouping similar acuity patients and then testing whether altitude could explain differences. ${ }^{18}$ Our propensity-matched analysis demonstrated altitude to be an independent predictor of survival. With the baseline characteristics accounted for in our survival model, it is more difficult to assert that differences in the baseline characteristics truly accounted for our findings. We further extended our analysis to identify survival factors with hazard ratios that were significantly different at high and low altitude. We observed that a given factor could paradoxically exert a beneficial influence at 1 altitude strata and harm at the other. For example, diabetes was associated with improved survival at 5 and 10 years after transplantation among patients above $2000 \mathrm{ft}$ but was associated with worsened survival below $2000 \mathrm{ft}$. Perhaps the most unifying theme of this secondary analysis was the observation that status $1 \mathrm{~A}$ patients were associated with improved survival above $4000 \mathrm{ft}$. Future studies might focus on this subset of patients to identify what features of the status 1A patients contributed to improved survival. One could speculate that this group of patients included stable patients with a LVAD who underwent transplantation during their "free" 30 day period of $1 \mathrm{~A}$ time, rather than the traditional 1A patient. Although no significant relationship relative to LVAD use at listing was found using our propensitymatched analysis comparing survival factors at high and low altitudes, the Cox models without propensity matching demonstrated consistent improvement in survival among the patients with a LVAD (Tables E1 and E2). Although the designation of status 1A markedly improved the outcomes in the higher altitude group, the wait times on the status 1A list had the opposite effect. Longer wait times 

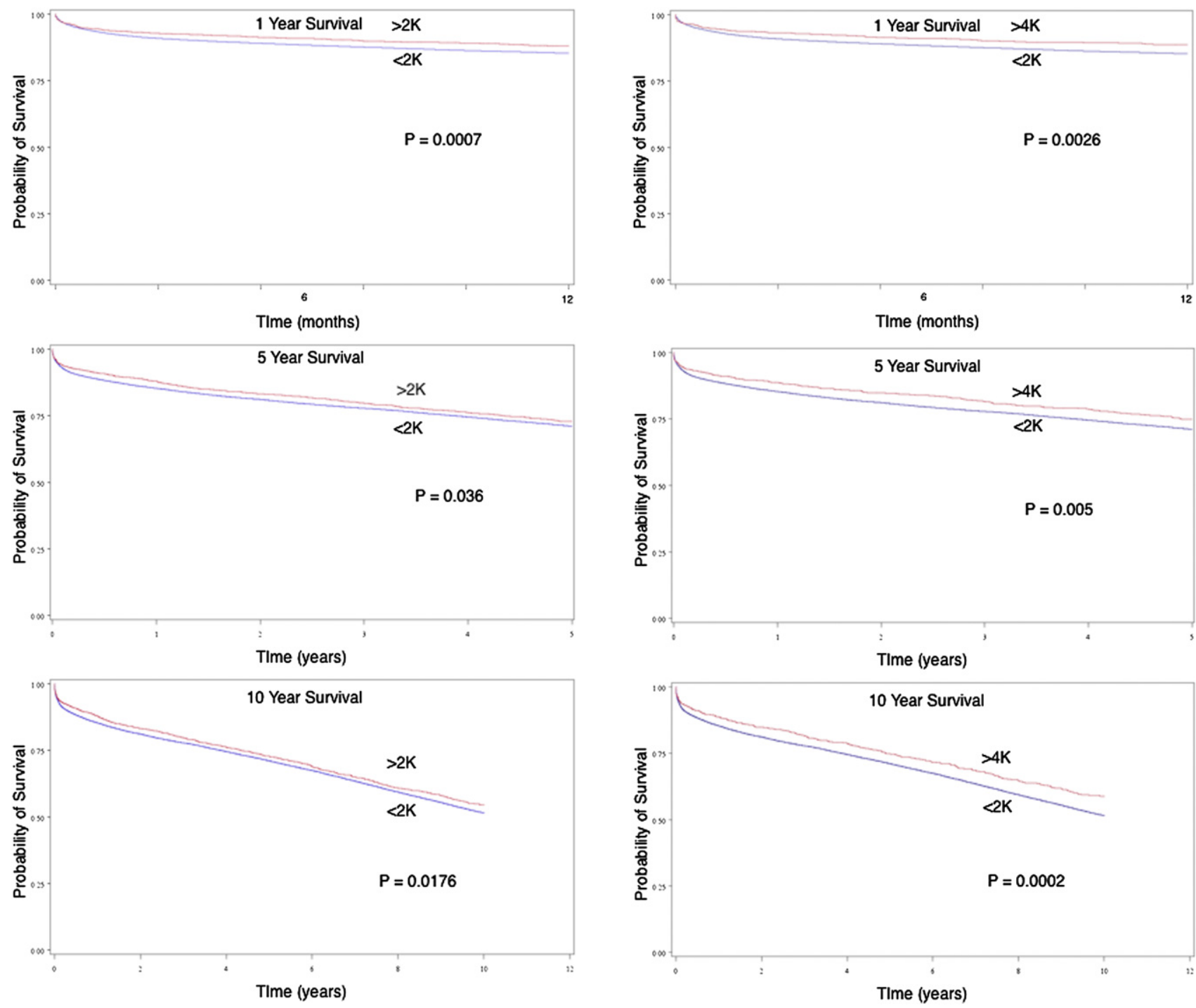

FIGURE 1. Survival at 1, 5, and 10 years for adult heart transplantations performed from 1990 to 2008, stratified by the patient's home altitude, less than $2000 \mathrm{ft}$ versus $2000 \mathrm{ft}$ or more.

FIGURE 2. Survival at 1,5 , and 10 years for adult heart transplantations performed from 1990 to 2008, stratified by patient's home altitude, less than $2000 \mathrm{ft}$ versus $4000 \mathrm{ft}$ or more.

for status $1 \mathrm{~A}$ patients living above $4000 \mathrm{ft}$ were associated with greater risk than for their counterparts living below $2000 \mathrm{ft}$. This last observation once again raises the importance of propensity-matched analysis. At baseline, patients above $4000 \mathrm{ft}$ had significantly shorter wait times than their counterparts below $2000 \mathrm{ft}$; however, their risk of death (at 5 and 10 years) was greater as the wait times lengthened. This observation was the most consistent across time and altitude strata, although we concede that the increased risk was low.

Tables 2 and 3 summarize the survival factors that were significantly different among the high and low altitude groups. The factors that are not listed, and therefore were not significant, were notable. Cigarette use, pulmonary artery pressures, and panel of reactive antibodies were all significantly different at baseline. However, after

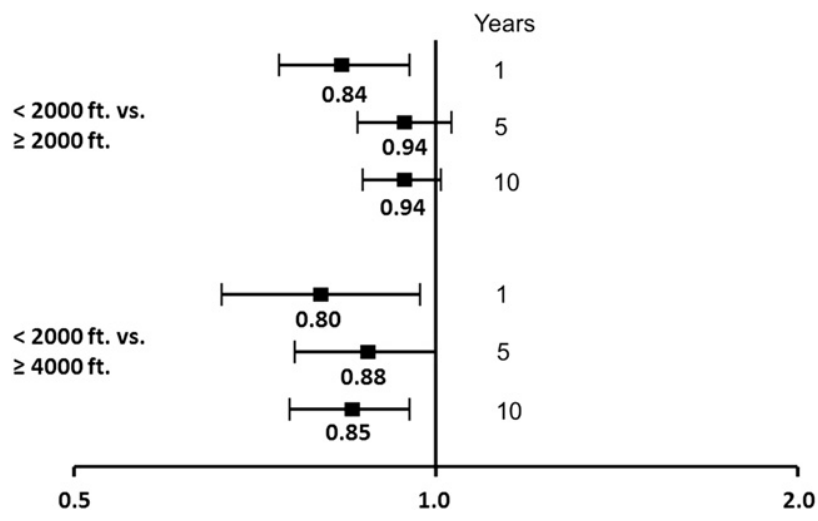

FIGURE 3. Horizontal error bar chart summarizing hazard ratios from the propensity matched Cox proportional hazard analysis. 
TABLE 2. Comparison of significant survival factors $<2000 \mathrm{ft}$ versus $\geq 2000 \mathrm{ft}$

\begin{tabular}{|c|c|c|c|c|}
\hline \multirow[b]{2}{*}{ Parameter } & \multicolumn{2}{|c|}{ Hazard ratio } & \multirow[b]{2}{*}{$P$ value* } & \multirow[b]{2}{*}{ Interval after transplantation $(y)$} \\
\hline & High altitude $(>2000 \mathrm{ft})$ & Low altitude $(<2000 \mathrm{ft})$ & & \\
\hline \multicolumn{5}{|l|}{ Benefit } \\
\hline Duration of status 1A (d) & 0.99 & 1.001 & .01 & 10 \\
\hline Diabetes & 0.85 & 1.194 & .02 & 5 \\
\hline & 0.9 & 1.22 & .02 & 10 \\
\hline \multicolumn{5}{|l|}{ Risk } \\
\hline Duration of status 1A (d) & 1.011 & 1.001 & .043 & 1 \\
\hline Male & 1.1 & 0.86 & .04 & 5 \\
\hline $\mathrm{VO}_{2} \mathrm{Max}$ & 1.03 & 0.96 & .02 & 10 \\
\hline
\end{tabular}

$\mathrm{VO}_{2} \mathrm{Max}$, Maximal exercise oxygen consumption. *Independent sample $t$ test $<2000$ versus $>2000 \mathrm{ft}$.

completion of the propensity-matched analysis, they were not found to explain the differences in survival.

In interpreting these results, the period of the data set must be considered. This cohort of patients treated from 1990 to 2008 does not reflect the significant changes that occurred with the change in heart organ allocation that occurred in 2006. ${ }^{19}$ This policy was initiated to reduce death on the waiting list by expanding regional organ sharing to allow heart allocation to the sickest recipients within the region. We and others have reported that these changes have resulted in a greater proportion of status $1 \mathrm{~A}$ transplantation, longer wait times, and longer ischemic times, without a change in mortality. ${ }^{20}$ Before 2006 , if no status I recipients were available, the organs were next prioritized within a given organ procurement organization to local status 2 patients. The older system probably favored transplantation of more status 2 patients at centers above $2000 \mathrm{ft}$ simply because the pool of eligible status 1 patients was small relative to the more populated centers below $2000 \mathrm{ft}$. The present study encompassed only 2 years of the new allocation system, and we presume that the effect of the allocation changes will be better seen over a longer period.

Although our analysis has identified factors that might aid in explaining our findings, the analysis still seems to lack a unifying explanation. This might be related to

TABLE 3. Comparison of significant survival factors for $<2000$ versus $\geq 4000 \mathrm{ft}$

\begin{tabular}{lcccc}
\hline & \multicolumn{2}{c}{ Hazard ratio } & & \\
\cline { 2 - 3 } Parameter & $\begin{array}{c}\text { High } \\
(>\mathbf{4 0 0 0} \mathbf{f t})\end{array}$ & $\begin{array}{c}\text { Low } \\
(<\mathbf{2 0 0 0} \mathbf{~ f t})\end{array}$ & $\begin{array}{c}\boldsymbol{P} \\
\text { value* }\end{array}$ & $\begin{array}{c}\text { Interval after } \\
\text { transplantation }(\mathbf{y})\end{array}$ \\
\hline Benefit & & & & \\
$\quad$ Status 1A & & & & \\
& 0.42 & 1.089 & .007 & 5 \\
& 0.47 & 1.06 & .009 & 10 \\
Risk & & & & \\
Duration of & & & & \\
$\quad$ status 1A (d) & & & & \\
& 1.012 & 1.001 & .03 & 5 \\
& 1.011 & 1.001 & .06 & 10 \\
\hline
\end{tabular}

*Independent sample $t$ test. limitations inherent in a database review in which a limited number of factors can be accurately accounted or measured. One factor obviously missing from our analysis is related to acute rejection. However, within the existing data set, it was not possible to obtain an accurate incidence of acute rejection. Too many values were missing, and the rate of reporting varied tremendously during study period, making the data unreliable.

Another factor that might be very important in explaining our findings is the altitude of the donor heart. Before 2006, organ allocation favored local recipients. As such, increased survival might have been a result of an already entrained right ventricle in a heart that originated and was transplanted at altitude. The limits of the UNOS data set prevented us from accurately assigning donor heart altitude. The donor state is available, but these data are confounded by the wide variations of altitudes among several Western states (eg, California, Oregon, and Washington).

The previous work in heart transplantation and altitude has been case studies demonstrating the relative safety of transplant patients performing exercise at altitude. ${ }^{12-14}$ In contrast, the interest on the effect of altitude on patients with coronary artery disease has been fairly significant. The experience gained from these population-based studies helps to put our findings in context. In an early study in New Mexico, the mortality from coronary artery disease was lower as the patient's home altitude increased. ${ }^{3}$ The benefit appeared to begin at $5000 \mathrm{ft}$ and preferentially advantaged male, but not female, patients. In our series, gender did not appear to play a role from the regression analysis.

With any observational study examining the effects of altitude, one must consider issues related to migration. Within the UNOS data set, we cannot determine whether patients underwent transplantation at a high altitude center and subsequently moved to a lower elevation or the reverse. In the study by Mortimer and colleagues, ${ }^{3}$ they followed up their patients for several years and found that traveling to lower altitude was infrequent. A more contemporary study of patients with coronary artery disease in Switzerland also addressed migration. $^{2}$ They demonstrated a reduction in 
mortality in patients living at high altitude. The investigators then tracked migration over the patients' lifetime and identified durable protective effects in patients born at high altitude who later moved to a lower altitude. Again, this beneficial effect was more pronounced for the male patients than for the female patients, and they attributed this difference to increased exercise in their male patients. The investigators offered several nontraditional factors that could have influenced their observation, including increased ultraviolet exposure/vitamin D use and improved cardiovascular-protective nutrients from food products raised at altitude.

Another population-based study from Greece comparing coronary deaths between sea-level and mountain (3100 ft) inhabitants found similar reductions in cardiac-related death among residents at altitude. ${ }^{1}$ Again, the effect was more pronounced for the male patients. The present study controlled for traditional cardiac risk factors (ie, lipids, hypertension, diabetes) and found that despite the lower incidence of cardiac deaths, residents at altitude had a greater incidence of cardiac risk factors than those at sea level. Similarly, the improvements in survival were theorized to result from increased exercise among mountain dwellers.

Admittedly, defining the mechanism behind our observed survival improvement is challenging. Although patients at higher altitude appeared to be less sick than those at lower altitudes, we cannot claim that these differences were related, as the previously cited studies did, to simply lifestyle (eg, more frequent exercise). Was our original hypothesis falsely derived? The intention of the studies on altitude and coronary disease was not to identify an underlying physiologic explanation of exposure to moderate altitude. Significant physiologic changes (ie, pulmonary hypertension, right ventricular hypertrophy) are not thought to occur until around $9800 \mathrm{ft}$ (3000 meters). ${ }^{21}$ Quite possibly, significant and independently associated restriction of the pulmonary vascular bed does not occur until altitudes well above any of those in the continental United States.

Alternatively, the well-described effects of high altitude on pulmonary hypertension might be balanced by its salubrious physiologic effects. For example, exposure to a high altitude has been shown to be associated with improved functional recovery from ischemic insult, a reduction in infarct size after ischemia, oxygen transport, mitochondrial biogenesis, and the efficiency of energy production. ${ }^{5,22}$ Coronary blood flow and angiogenesis are also thought to improve as a result of exposure to a high altitude, although 1 study found that patients with coronary artery disease living at moderate altitude lose the ability to augment coronary flow. ${ }^{23}$ Right ventricular function is enhanced in response to pulmonary hypertension, although this adaptation can become maladaptive in the context of chronic mountain sickness and subacute mountain sickness when the pulmonary vascular bed becomes hyper-reactive. ${ }^{24}$

In conclusion, and contrary to our initial hypothesis, patients living above $2000 \mathrm{ft}$ have improved survival after heart transplantation. The survival advantage is even more significant for patients living above $4000 \mathrm{ft}$. These observations should allay some of the fears patients and physicians living at higher elevations might have when considering their candidacy for heart transplantation. Although the patients at higher altitude had a lower incidence of tobacco use and diabetes, these factors did not explain the differences in survival between the groups. Status 1A patients living above $4000 \mathrm{ft}$ were associated with improved survival. Although the reasons for this are uncertain, this could potentially aid in explaining our findings. It remains unclear whether other unidentified factors might play a heretofore unrecognized role in predicting survival. The altitude of the donor heart could be an important factor. Future studies are needed to account for the relatively recent change in organ allocation policy to standardize the degree of urgency among patients at any altitude.

\section{References}

1. Baibas N, Trichopoulou A, Voridis E, Trichopoulos D. Residence in mountainous compared with lowland areas in relation to total and coronary mortality: a study in rural Greece. J Epidemiol Commun Health. 2005;59:274-8.

2. Faeh D, Gutzwiller F, Bopp M. Lower mortality from coronary heart disease and stroke at higher altitudes in Switzerland. Circulation. 2009;120:495-501.

3. Mortimer EA Jr, Monson RR, MacMahon B. Reduction in mortality from coronary heart disease in men residing at high altitude. $N$ Engl J Med. 1977;296: 581-5.

4. Ezzati M, Horwitz ME, Thomas DS, Friedman AB, Roach R, Clark T, et al. Altitude, life expectancy and mortality from ischaemic heart disease, stroke, COPD and cancers: national population-based analysis of US counties. $J$ Epidemiol Commun Health. Epub 2011 Mar 15.

5. Ostadal B, Kolar F. Cardiac adaptation to chronic high-altitude hypoxia: beneficial and adverse effects. Respir Physiol Neurobiol. 2007;158:224-36.

6. Klausen K. Cardiac output in man in rest and work during and after acclimatization to 3,800 m. J Appl Physiol. 1966;21:609-16.

7. Huez S, Faoro V, Guenard H, Martinot JB, Naeije R. Echocardiographic and tissue Doppler imaging of cardiac adaptation to high altitude in native highlanders versus acclimatized lowlanders. Am J Cardiol. 2009;103:1605-9.

8. Tune JD. Control of coronary blood flow during hypoxemia. Adv Exp Med Biol. 2007;618:25-39.

9. Naeije R. Physiological adaptation of the cardiovascular system to high altitude. Prog Cardiovasc Dis. 2010;52:456-66.

10. Mazzeo RS, Reeves JT. Adrenergic contribution during acclimatization to high altitude: perspectives from Pikes Peak. Exerc Sport Sci Rev. 2003;31:13-8.

11. Palatini P, Businaro R, Berton G, Mormino P, Rossi GP, Racioppa A, et al. Effects of low altitude exposure on 24-hour blood pressure and adrenergic activity. Am J Cardiol. 1989;64:1379-82.

12. Roi GS, Mosconi G, Capelli I, Cuna V, Persici E, Parigino M, et al. Alpine skiing and anaerobic performance in solid organ transplant recipients. Transplant Proc. 2010;42:1029-31.

13. White M, Touyz R, Tessier Y, Van Le V, Ross H, Sirois MG. A cardiac and a kidney transplant patient above 6000 meters in Bolivia. Wilderness Environ Med. 2009;20:99-100.

14. Bedard S. Bolivia $6,000 \mathrm{~m}$ : achieving new heights after heart transplantation. J Heart Lung Transplant. 2006;25:160-1.

15. Stobierska-Dzierzek B, Awad H, Michler RE. The evolving management of acute right-sided heart failure in cardiac transplant recipients. J Am Coll Cardiol. 2001; 38:923-31

16. Delgado JF, Gomez-Sanchez MA, Saenz de la Calzada C, Sanchez V, Escribano P, Hernandez-Afonso J, et al. Impact of mild pulmonary hypertension 
on mortality and pulmonary artery pressure profile after heart transplantation. J Heart Lung Transplant. 2001;20:942-8.

17. Butler J, Stankewicz MA, Wu J, Chomsky DB, Howser RL, Khadim G, et al. Pretransplant reversible pulmonary hypertension predicts higher risk for mortality after cardiac transplantation. J Heart Lung Transplant. 2005;24:170-7.

18. Blackstone EH. Comparing apples and oranges. J Thorac Cardiovasc Surg. 2002; 123:8-15.

19. Directors UBo. Policy 3.7 Organ Distribution: allocation of thoracic organs. [Electronic] 2006. Available from: http://www.unos.org/PoliciesandBylaws2/ policies/pdfs/policy_9.pdf. Accessed June 12, 2011.

20. Nativi JN, Kfoury AG, Myrick C, Peters M, Renlund D, Gilbert EM, et al. Effects of the 2006 U.S. thoracic organ allocation change: analysis of local impact on organ procurement and heart transplantation. J Heart Lung Transplant. 2010 29:235-9.

21. Hurtado A. Some clinical aspects of life at high altitudes. Ann Internal Med. 1960;53:247-58

22. Essop MF. Cardiac metabolic adaptations in response to chronic hypoxia. J Physiol. 2007;584(Pt 3):715-26

23. Wyss CA, Koepfli P, Fretz G, Seebauer M, Schirlo C, Kaufmann PA. Influence of altitude exposure on coronary flow reserve. Circulation. 2003;108: 1202-7.

24. Penaloza D, Arias-Stella J. The heart and pulmonary circulation at high altitudes: healthy highlanders and chronic mountain sickness. Circulation. 2007;115: 1132-46. 
TABLE E1. Cox regression analysis comparing survival factors $<2000 \mathrm{ft}$ versus $\geq \mathbf{2 0 0 0} \mathrm{ft}$

\begin{tabular}{|c|c|c|c|c|c|c|c|c|c|c|c|c|c|c|c|}
\hline \multirow[b]{3}{*}{ Variable } & \multicolumn{5}{|c|}{$1 \mathbf{y}$} & \multicolumn{5}{|c|}{5 years } & \multicolumn{5}{|c|}{10 years } \\
\hline & \multicolumn{2}{|c|}{$<2000$ ft } & \multicolumn{2}{|c|}{$>2000 \mathrm{ft}$} & \multirow{2}{*}{$\begin{array}{c}<2000 \mathrm{vs} \\
>2000 \mathrm{ft} \\
P \\
\text { value* }^{*}\end{array}$} & \multicolumn{2}{|c|}{$<2000$ ft } & \multicolumn{2}{|c|}{$>2000 \mathrm{ft}$} & \multirow{2}{*}{$\begin{array}{c}<2000 \mathrm{vs} \\
>2000 \mathbf{f t} \\
P \\
\text { value }^{*}\end{array}$} & \multicolumn{2}{|c|}{$<\mathbf{2 0 0 0} \mathbf{f t}$} & \multicolumn{2}{|c|}{$>2000 \mathrm{ft}$} & \multirow{2}{*}{$\begin{array}{c}<2000 \mathrm{vs} \\
>2000 \mathrm{ft} \\
P \\
\text { value* }^{*}\end{array}$} \\
\hline & HR & $\begin{array}{c}P \\
\text { value }\end{array}$ & HR & $\begin{array}{c}P \\
\text { value }\end{array}$ & & HR & $\begin{array}{c}P \\
\text { value }\end{array}$ & HR & $\begin{array}{c}P \\
\text { value }\end{array}$ & & HR & $\begin{array}{c}P \\
\text { value }\end{array}$ & HR & $\begin{array}{c}P \\
\text { value }\end{array}$ & \\
\hline Age & 1.01 & $<.0001$ & 1.01 & .04 & .41 & 1.00 & .63 & 1.01 & .16 & .21 & 1.00 & $<.0001$ & 1.01 & $<.01$ & .07 \\
\hline Male & 0.89 & $<.001$ & 1.01 & .96 & .45 & 0.86 & $<.0001$ & 1.07 & .56 & .08 & 0.89 & $<.0001$ & 1.00 & 1.00 & .24 \\
\hline BMI & 1.00 & .75 & 1.00 & .97 & .99 & 1.00 & .73 & 1.00 & .71 & .75 & 1.00 & .73 & 1.00 & .41 & .38 \\
\hline Status 1A & 1.11 & .02 & 1.05 & .83 & .80 & 1.03 & .42 & 0.94 & .71 & .60 & 1.01 & .84 & 0.94 & .72 & .70 \\
\hline $\begin{array}{r}\text { Duration of } \\
\text { status 1A }\end{array}$ & 1.00 & .57 & 1.01 & .03 & .35 & 1.00 & .10 & 1.01 & .07 & .13 & 1.00 & .10 & 1.01 & .17 & .28 \\
\hline Diabetes & 1.12 & .01 & 0.75 & .18 & .07 & 1.18 & $<.0001$ & 0.86 & .29 & .04 & 1.21 & $<.0001$ & 0.92 & .49 & .03 \\
\hline LVAD at listing & 1.17 & .11 & 0.35 & .15 & .10 & 1.10 & .25 & 0.32 & .06 & .04 & 1.12 & .19 & 0.33 & .06 & .04 \\
\hline Mean PAP & 1.01 & $<.0001$ & 1.02 & .03 & .42 & 1.01 & $<.0001$ & 1.01 & .06 & .64 & 1.00 & $<.001$ & 1.01 & .04 & .26 \\
\hline HLA mismatch & 1.06 & $<.0001$ & 1.11 & .09 & .50 & 1.06 & $<.0001$ & 1.11 & .01 & .24 & 1.04 & $<.0001$ & 1.09 & .01 & .18 \\
\hline PRA & 1.01 & $<.0001$ & 1.01 & .01 & .55 & 1.00 & $<.0001$ & 1.01 & .02 & .41 & 1.00 & $<.0001$ & 1.01 & .02 & .33 \\
\hline Ischemic time & 1.20 & $<.0001$ & 1.12 & .05 & .27 & 1.13 & $<.0001$ & 1.11 & .01 & .66 & 1.10 & $<.0001$ & 1.07 & .03 & .58 \\
\hline $\mathrm{VO}_{2} \mathrm{Max}$ & 0.95 & $<.0001$ & 0.93 & .11 & .74 & 0.96 & $<.0001$ & 1.02 & .63 & 0.11 & 0.96 & $<.0001$ & 1.02 & .49 & .05 \\
\hline Tobacco use & 0.72 & $<.0001$ & 0.70 & .27 & .93 & 0.82 & $<.001$ & 1.13 & .59 & .18 & 0.81 & $<.0001$ & 1.12 & .59 & .14 \\
\hline
\end{tabular}

$B M I$, Body mass index; $L V A D$, left ventricular assist device; $P A P$, pulmonary artery pressure; $H L A$, human leukocyte antigen; $P R A$, panel of reactive antibodies; $V O_{2} M a x$, maximal exercise oxygen consumption. *Independent sample $t$ test comparing magnitude of effect between $<2000 \mathrm{vs}>2000 \mathrm{ft}$.

TABLE E2. Cox regression comparing survival factors $<2000 \mathrm{vs} \geq \mathbf{4 0 0 0} \mathrm{ft}$

\begin{tabular}{|c|c|c|c|c|c|c|c|c|c|c|c|c|c|c|c|}
\hline \multirow[b]{3}{*}{ Variable } & \multicolumn{5}{|c|}{$1 \mathrm{y}$} & \multicolumn{5}{|c|}{$5 \mathbf{y}$} & \multicolumn{5}{|c|}{$10 y$} \\
\hline & \multicolumn{2}{|c|}{$<2000 \mathbf{f t}$} & \multicolumn{2}{|c|}{$>4000 \mathrm{ft}$} & \multirow{2}{*}{$\begin{array}{c}<2000 \mathrm{vs} \\
>4000 \mathrm{ft} \\
P \\
\text { value* }^{*}\end{array}$} & \multicolumn{2}{|c|}{$<2000 \mathrm{ft}$} & \multicolumn{2}{|c|}{$>4000 \mathrm{ft}$} & \multirow{2}{*}{$\begin{array}{c}<2000 \mathrm{vs} \\
>4000 \mathrm{ft} \\
P \\
\text { value }^{*}\end{array}$} & \multicolumn{2}{|c|}{$<2000 \mathrm{ft}$} & \multicolumn{2}{|c|}{$>4000 \mathrm{ft}$} & \multirow{2}{*}{$\begin{array}{c}<2000 \mathrm{vs} \\
>4000 \mathrm{ft} \\
P \\
\text { value }^{*}\end{array}$} \\
\hline & HR & $\begin{array}{c}P \\
\text { value }\end{array}$ & HR & $\begin{array}{c}P \\
\text { value }\end{array}$ & & HR & $\begin{array}{c}P \\
\text { value }\end{array}$ & HR & $\begin{array}{c}P \\
\text { value }\end{array}$ & & HR & $\begin{array}{c}P \\
\text { value }\end{array}$ & HR & $\begin{array}{c}P \\
\text { value }\end{array}$ & \\
\hline Age & 1.01 & $<.0001$ & 1.03 & .01 & .05 & 1.00 & .63 & 1.01 & .03 & .04 & 1.00 & $<.0001$ & 1.01 & .02 & .10 \\
\hline Male & 0.89 & $<.001$ & 0.78 & .33 & .62 & 0.86 & $<.0001$ & 0.85 & .36 & .91 & 0.89 & $<.0001$ & 0.83 & .22 & .66 \\
\hline BMI & 1.00 & .75 & 1.00 & .82 & .84 & 1.00 & .73 & 1.00 & .72 & .73 & 1.00 & .73 & 1.00 & .42 & .38 \\
\hline Status 1A & 1.11 & .02 & 0.51 & .09 & .06 & 1.03 & .42 & 0.43 & .01 & .01 & 1.01 & .84 & 0.53 & .02 & .03 \\
\hline $\begin{array}{r}\text { Duration of } \\
\text { status } 1 \mathrm{~A}\end{array}$ & 1.00 & .57 & 1.01 & .02 & .04 & 1.00 & .10 & 1.01 & .01 & .02 & 1.00 & .10 & 1.01 & .01 & .02 \\
\hline Diabetes & 1.12 & .01 & 1.03 & .93 & .80 & 1.18 & $<.0001$ & 1.11 & .64 & .79 & 1.21 & $<.0001$ & 1.11 & .62 & .65 \\
\hline LVAD at listing & 1.17 & .11 & 0.29 & .23 & .19 & 1.10 & .25 & 0.19 & .10 & .09 & 1.12 & .19 & 0.19 & .11 & .09 \\
\hline Mean PAP & 1.01 & $<.0001$ & 1.03 & .01 & .08 & 1.01 & $<.0001$ & 1.01 & .08 & .38 & 1.00 & $<.001$ & 1.01 & .66 & .17 \\
\hline HLA mismatch & 1.06 & $<.0001$ & 1.08 & .35 & .80 & 1.06 & $<.0001$ & 1.08 & .23 & .75 & 1.04 & $<.0001$ & 1.07 & .18 & .57 \\
\hline PRA & 1.01 & $<.0001$ & 1.01 & .21 & .98 & 1.00 & $<.0001$ & 1.01 & .25 & .86 & 1.00 & $<.0001$ & 1.01 & .13 & .58 \\
\hline Ischemic time & 1.20 & $<.0001$ & 1.35 & .02 & .21 & 1.13 & $<.0001$ & 1.26 & .01 & .09 & 1.10 & $<.0001$ & 1.18 & .01 & .20 \\
\hline $\mathrm{VO}_{2} \mathrm{Max}$ & 0.95 & $<.0001$ & 1.00 & .95 & .46 & 0.96 & $<.0001$ & 1.05 & .31 & .08 & 0.96 & $<.0001$ & 1.05 & .37 & .08 \\
\hline Tobacco use & 0.72 & $<.0001$ & 0.68 & .45 & .91 & 0.82 & $<.001$ & 1.41 & .36 & .16 & 0.81 & $<.0001$ & 1.27 & .49 & .21 \\
\hline
\end{tabular}

$B M I$, Body mass index; $L V A D$, left ventricular assist device; $P A P$, pulmonary artery pressure; $H L A$, human leukocyte antigen; $P R A$, panel of reactive antibodies; $V O_{2} M a x$, maximal exercise oxygen consumption. *Independent sample $t$ test comparing magnitude of effect between $<2000 \mathrm{vs}>4000 \mathrm{ft}$. 